\title{
Mixed Ownership, Managerial Incentives and Bank Competition*
}

\author{
Bibhas Saha $^{\dagger}$
}

Rudra Sensarma

\begin{abstract}
We consider deposit competition between two banks, where prior to competition one bank is subjected to a nationalization decision and the other bank chooses managerial incentives. The government who maximizes a modified form of social welfare (with greater weight on profit than depositor surplus) chooses only partial nationalization, which still hurts the rival private bank. But by offering deposit-linked managerial incentives the private bank recovers its lost profit and induces even less nationalization, leaving social welfare unchanged. However, under interest rate competition for differentiated deposits the private bank offers profit-linked managerial incentives while the other bank may be completely nationalized.
\end{abstract}

Keywords: banking, privatization, nationalization, mixed duopoly, managerial incentive JEL classification numbers: G21, L13, L33.

\footnotetext{
${ }^{*}$ Correspondence: Dr Rudra Sensarma, University of Hertfordshire Business School, Hatfield, Herts, AL10 9AB, UK. Tel: +44 (0) 1707285456; Fax: +44 (0) 1707285455; Email: rsensarma@gmail.com.

${ }^{\dagger}$ School of Economics, University of East Anglia, Norwich, NR4 7TJ, UK; E-mail: b.saha@uea.ac.uk

${ }_{\ddagger}^{\ddagger}$ Department of Accounting, Finance and Economics, University of Hertfordshire Business School, Hatfield, Herts, AL10 9AB, UK; E-mail: rsensarma@gmail.com.
} 


\section{Introduction}

Mixed ownership in banking is a common feature across different economic systems. While profit considerations led to privatization of many state-owned banks in transition economies, state presence has been frequently observed in banking sectors all over the world. See Barth et al (2001) for evidence on EU countries, Sherif et al (2003) for transition economies and Shirai (2002) for China and India. Even in the Anglo-Saxon economies, the recent credit crisis of 2007 subsequently led to nationalization of many banks and financial institutions. At the same time, entry of private and foreign banks is typically subject to state control. There is also wide-spread evidence of managerial incentive schemes in the corporate world including in banks. ${ }^{1}$ While such incentives are usually profit enhancing, it is also believed that they were partly responsible for the recent failures of the banking industry. It is, therefore, reasonable to expect that the banking industry in many economies resembles mixed oligopoly with strategic interactions among banks occurring at many dimensions. We study such interactions between a partially public bank and a private bank by allowing the former to choose the degree of public ownership and the latter managerial incentive prior to engaging in deposit or interest rate competition. Examining such interactions will also help us understand some elements of the recent banking crisis.

We assume that the government is a social welfare maximizer, but is also somewhat profit oriented. This profit orientation forces the government to privatize the public bank to some extent, even if there is no other bank in the market. The presence of another bank makes the government internalize some of the strategic effects that state ownership, howsoever partial, might have on the other bank's profit. On its part, the private bank can counter the competitiveness of the public bank by offering revenue-linked incentives to its manager. The combination of managerial incentives and profit orientation will cause even greater privatization of the public bank. As a consequence, a particular type of mixed duopoly emerges in which privatization is always partial and the private bank always

\footnotetext{
${ }^{1}$ See Jensen et al (2004) for a comprehensive review of managerial incentives and Hubbard and Palia (1995) for evidence from U.S. banking. On emerging economies, see Eriksson (2005) and Kato and Long (2006) for evidence on pay-performance relationships in the Czech Republic and China.
} 
departs from (pure) profit maximization. More interestingly, in this mixed duopoly the government's profit orientation determines a certain level of industry profit, and the private bank's managerial incentives scheme forces a transfer of profit from the public bank to the private bank leaving the social welfare unchanged. This pure redistributive role of managerial incentives is possible only in a mixed duopoly, and this has not been identified earlier in the literature.

We also observe that the combination of partial nationalization and managerial incentive improves social welfare from the level of pure duopoly (involving only private banks) without managerial incentive. Since we assume that there is no competition in the loan market, this result suggests that in the context of the recent banking crisis nationalization and managerial incentive (in the deposit market) might be helpful if competition in the loan market is somewhat muted. ${ }^{2}$

We then consider the case of interest rate competition with deposit differentiation where we show that the private bank will offer profit-linked incentives to its manager in equilibrium. The reason for incentives to be profit-linked is that the interest rate appears on the cost side of the private bank's balance sheet and two interest rates are strategic complements. Therefore, by linking reward to profit the managers are essentially induced to cut the interest rate, which will be reciprocated by the other bank as well (due to strategic complementarity). This is consistent with the price competition result of Fershtman and Judd (1987). As for privatization, the result depends on the degree of deposit differentiation. If the two markets are fairly apart then the government does not worry about the adverse effects of nationalization on the private bank (because such effects would be minimal) and maximizes social welfare through full nationalization. On the other hand, if the two deposits are close substitutes then the government cares about the adverse effects spilling over to the second market, and tends to reduce the public bank's interest rate by undertaking partial privatization. Here, due to deposit differentiation it is difficult to

\footnotetext{
${ }^{2}$ The recent asset protection scheme of the UK government, that insures bank loans, eliminates downside risks in lending and is similar to providing a safe rate of return which we have assumed in our model. This scheme will moderate competition in the loan market and mitigate the risk profiles of participating banks.
} 
ascertain whether the managerial incentives are merely redistributive as they were under deposit competition. Nevertheless, here too managerial incentives are proving to be an effective means of countering the effects of nationalization.

While there is a vast literature on bank competition starting from the works of Monti (1972) and Klein (1971), non-profit maximizing motives in banking have been rarely examined. Purroy and Salas (2000) studied competition between a profit maximizing private bank and a savings institution. Their savings institution exhibits 'expense preference behavior', i.e. utility maximization where utility is a weighted average of profit and workers' wage-bill. They show that the private bank can partly restore the asymmetry created by the savings institution's utility function by offering managerial incentives. However their results cannot be generalized to public banks and the question of privatization cannot be addressed. Our model tries to fill this gap.

There are many papers that have studied mixed duopoly, but partial privatization concerns only a few (such as Fershtman, 1990; Matsumura, 1998). Even fewer papers have studied mixed duopoly in the banking context (except Purroy and Salas, 2000; Saha and Sensarma, 2004). But there is a large literature on managerial incentives following the seminal work of Vickers (1985), Fershtman and Judd (1987) and Sklivas (1987). We integrate these two literatures with the objective of simultaneously determining optimal privatization and managerial incentives.

The paper is organized as follows. Section 2 sets out the basic model and section 3 discusses optimal privatization and managerial incentives. Section 4 considers the case of interest rate competition. The concluding section discusses policy implications.

\section{The Model}

We consider a two-stage game between a partially public and a fully private bank. In the first stage, the government decides on the share of public ownership in the partially public bank, while the private bank decides on managerial incentives. In the second stage the 
two banks engage in deposit competition. ${ }^{3}$ Profits are subsequently realized. We solve the game by backward induction i.e. we first derive the equilibrium deposits (stage 2) and then the equilibrium ownership and managerial incentives of the public bank and private bank respectively (stage 1 ).

The public bank is indexed 0, and the private bank indexed 1. Depositors are paid interest rate $r$ by the following rule: $r=b\left(D_{0}+D_{1}\right), b>0$. Here $D_{0}$ and $D_{1}$ are the deposits collected by the public and the private bank respectively while $b$ denotes the slope of the deposit supply curve. On the revenue side, both banks face a constant rate of return $R$ on each unit of investment made out of these deposits. ${ }^{4}$ Fixed $R$ can be justified by assuming that money markets and loan markets are competitive, where banks are price takers, though they can have market power in raising deposits. The public bank is jointly owned by the government and a private partner, and the choice of the volume of deposit is made by the bank's board of management consisting of a government representative ${ }^{5}$ and the private partner. If the private partner had full ownership, it would have maximized $\pi_{0}=(R-r) D_{0}$ by choosing $D_{0}$ as

$$
D_{0}=\frac{R-b D_{1}}{2 b}
$$

Denote this hypothetical reaction function as $R F_{0}$. On the other hand, if the bank was under full state ownership, the government representative in the public bank would maximize social welfare, which is defined as the sum of depositor surplus $(D S)$ and profit, and given by $S W=D S+\sum_{0}^{1} \pi_{i}$, where $D S=r D-\int_{0}^{D} b z d z=r D-\frac{b D^{2}}{2}=\frac{b D^{2}}{2}$, or $S W=\left(R-\frac{b D}{2}\right) D$, where $D=D_{0}+D_{1}$. The government representative would maximize

\footnotetext{
${ }^{3}$ When interest rate is regulated, as in many developing economies, banks tend to compete more in deposit.

${ }^{4}$ This is a simplification. The basic qualitative results do not change if $R$ varies inversely with $D$. However that would require an analysis of the loan market which we abstract from in this paper. We can also allow for a statutory reserve ratio, in which case $R$ is to be taken as an average rate of return, averaged over the reserve deposit and investible deposit.

${ }^{5}$ An example is UK Financial Investments, the company set up by the UK government to manage its stakes in partially nationalized banks.
} 
$S W$ by choosing $D_{0}$ as

$$
D_{0}=\frac{R-b D_{1}}{b}
$$

which would have been its reaction function. We denote it as $R \tilde{F}_{0}$.

However, there must be a balance between the profit maximizing objective of the private partner and the social welfare objective of the government representative. This can be modeled in a number of ways. We take the approach suggested by Fershtman (1990) in which the public bank's deposit choice is given by a weighted reaction function, where weights are applied on the two extreme reaction functions - fully public (2) and fully private (1), and the weights directly correspond to their respective shares of ownership. Thus, the reaction function of the public bank is $R F_{0}=\theta \hat{R F_{0}}+(1-\theta) R \hat{F}_{0}$ where $\theta(\theta \in[0,1])$ is the degree of public ownership. ${ }^{6}$ This can be rewritten as

$$
D_{0}=\frac{(1+\theta)\left(R-b D_{1}\right)}{2 b}
$$

It is noteworthy that Fershtman (1990) did not provide an objective function of the partly nationalized firm leaving it an open issue. ${ }^{7}$ However, first Saha and Sensarma (2004) and then Kumar and Saha (2008) have suggested two alternative objective functions that can support Fershtman's reaction function. ${ }^{8}$ Either can be used as a justification in the present context.

While the public bank's deposit choice is specified in the above manner, it may be

\footnotetext{
${ }^{6}$ Even if there is some discontinuity at an ownership level of 50 percent, we assume that the bank's behavior is responsive to small changes in ownership.

${ }^{7}$ Fershtman (1990, pp. 327) cites Bos and Peters (1989) for a detailed discussion on the objective function of a partly nationalized firm. But the issue was, nevertheless, unsettled.

${ }^{8}$ Saha and Sensarma (2004) showed that if the government representative wanted to maximize the depositor surplus for the public bank's depositors, then Nash bargaining between him and the private partner would result in this reaction function. Kumar and Saha (2008) show that if the objective function of a partially public firm is given by a weighted average of social welfare and profit, which follows the approach of Matsumura (1998), then also the above reaction function emerges. In our model if we write the objective function of the partially public bank as: $\alpha S W+(1-\alpha) \pi_{0}=\alpha\left[R-\frac{b D}{2}\right] D+(1-\alpha)[R-r] D_{0}$, where $\alpha=\frac{2 \theta}{1+\theta}$, then by differentiating this objective function with respect to $D_{0}$ we arrive at the reaction function given by (3).
} 
preceded by a decision of how much to divest or privatize, and this decision lies at a higher level of government, whose concern is to maximize social welfare and possibly at the same time ensure solvency of the banks. Governments and regulators are known to be concerned about firm and industry performance especially in the banking industry where it is linked to financial stability. A variety of measures such as safety nets, recapitalization, entry regulation etc. are employed by governments to ensure that banks are solvent and profitable. Aghion et al (1999) emphasized the importance of solvency in their analysis of different bail-out rules for banks in transition economies. See also Allen and Gale (2004). ${ }^{9}$ While our model is deterministic and cannot allow for potential losses and bank runs, we introduce the concern of government for industry profits by modifying its objective function. Thus, the government chooses $\theta$ to maximize a modified social welfare function which places a higher weight on profit. The modified social welfare function is denoted as $V=D S+\beta\left(\pi_{0}+\pi_{1}\right)$ which can be rewritten as $V=S W+(\beta-1)\left(\pi_{0}+\pi_{1}\right) \cdot{ }^{10}$ With $\beta>1$, the government demonstrates its profit orientation by placing an additional positive weight on profit in its social welfare objective. An alternative formulation could be to set $\beta=1$ but place a profit constraint on the banks. ${ }^{11}$ Note that the government's objective function differs from the objective of the government representative in the public bank's management board. However, this difference is only in terms of the profit orientation.

The private bank, though technologically identical to its public counterpart, may hire a manager and offer her incentives to boost its profit. Following the strategic delegation literature (see Vickers, 1985; Fershtman and Judd, 1987; Skilvas, 1987), we assume a linear incentive scheme which may reward (or penalize) the manager for generating revenue beyond the standard profit maximizing level. Formally, the manager is instructed to choose $D_{1}$ to maximize $M=(1-\rho) \pi_{1}+\rho R D_{1}$.

\footnotetext{
${ }^{9}$ Allen and Gale (2004) write, "If the government is concerned with financial stability it may ensure that banks survive by regulating entry in different regions."

${ }^{10}$ Matsumura (1998) used a similar formulation in a non-banking context but with the government placing a higher weight on consumer surplus.

${ }^{11}$ Such a formulation would play an equivalent role as our modified social welfare function. Saha and Sensarma (2004) showed that when the public bank has to meet a reservation profit, the government is forced to restrict its degree of nationalization.
} 
Depending on the owner's preference, $\rho$ can take a wide range of values. The standard case of profit maximization is given by $\rho=0$. But if $\rho>0$, the manager is encouraged to pursue sales more than profit. Conversely, $\rho<0$ implies that the manager will be encouraged to pursue profit more than sales.

The manager maximizes the above objective function and her choice of $D_{1}$ gives the private bank's deposit reaction function

$$
D_{1}=\frac{R-(1-\rho) b D_{0}}{2 b(1-\rho)}
$$

The reaction curves of the two banks as given by (3) and (4) are shown in figure 1 . Two thick curves, denoted as $R F_{0}$ and $R F_{1}$ are drawn with the assumption that $\theta \in(0,1)$ and $\rho \in\left(0, \frac{1}{2}\right)$. The downward slopes indicate that the deposits are strategic substitutes. If the private bank chooses zero deposit, the public bank will choose its monopoly deposit as $\frac{(1+\theta) R}{2 b}$, and similarly, if the public bank chooses zero deposit the private bank's manager will choose $D_{1}=\frac{R}{2 b(1-\rho)}$. Conversely, if the private bank chooses $D_{1}=\frac{R}{b}$, the public bank will simply close down, and similarly, the public bank's choice of $D_{0}=\frac{R}{b(1-\rho)}$ will force the private bank to close down. Thus, the monopoly and entry-deterring levels of deposits of each bank can be defined in the usual way as quantity setting firms' outputs are defined. The equilibrium deposits are given by point $M$ comprising of $D_{0}^{*}$ and $D_{1}^{*}$, which we obtain as

$$
\begin{array}{r}
D_{0}=\frac{R(1+\theta)(1-2 \rho)}{b(3-\theta)(1-\rho)}, \\
D_{1}=\frac{R[(1-\theta)+\rho(1+\theta)]}{b(3-\theta)(1-\rho)} .
\end{array}
$$

It is clear that we must have $\rho<\frac{1}{2}$ for $D_{0}$ to be positive. If indeed it were the case that $\rho \geq \frac{1}{2}$, the public bank would be forced to close down, and the private bank would mobilize $D_{1}=\frac{R}{b}$; however its profit will fall to zero, which also suggests that the private bank will never set $\rho>\frac{1}{2}$. This extreme situation is described by the two dashed reaction curves. On the other extreme, if $\theta=0$ and both banks were profit-maximizers (i.e. $\rho=0$ ) we would 
have a pure duopoly. Both reaction curves would shift inward and we have the Cournot Deposits as $D_{0}=D_{1}=\frac{R}{3 b}$. This is given by point $N$ at the intersection of two thinner reaction curves. Since point $M$ lies North-East of $N$, it is clear that the mixed duopoly generates much greater individual and aggregate deposits than the private duopoly.

As can be seen from (5), managerial incentive of the private bank and privatization of the public bank will both favor the private bank, and hurt the public bank in terms of their deposit choice. Formally, $\frac{\partial D_{0}}{\partial \rho}<0, \frac{\partial D_{0}}{\partial \theta}>0, \frac{\partial D_{1}}{\partial \rho}>0, \frac{\partial D_{1}}{\partial \theta}<0$, if $\rho<\frac{1}{2}$.

Finally, if the private bank had set $\rho<0$, its output would fall against any given $\theta$, because its reaction function would shift inward starting from the situation of profit maximization. Consequently, its deposit would fall below the pure duopoly level. However, such a scenario is never profitable for the private bank. Therefore, we will not consider $\rho<0$. Henceforth, our attention will be restricted to $\rho \in\left[0, \frac{1}{2}\right]$ under deposit competition.

(Insert Figure 1 here)

\section{Optimal privatization and managerial incentives}

We now move to the first stage of the game and analyze the strategic interactions in terms of managerial incentives and privatization. For this we need to derive the private banks's profit and the government's modified social welfare from the second stage equilibrium. Utilizing (5) we get

$$
\begin{array}{r}
V=\frac{R^{2}[2-\rho(1+\theta)][2-\rho(1+\theta)+\beta(1-\theta)(1-2 \rho)]}{b(1-\rho)^{2}(3-\theta)^{2}} \\
\pi_{0}=\frac{R^{2}\left(1-\theta^{2}\right)(1-2 \rho)^{2}}{b(1-\rho)^{2}(3-\theta)^{2}} \\
\pi_{1}=\frac{R^{2}(1-\theta)(1-2 \rho)[(1-\theta)+\rho(1+\theta)]}{b(1-\rho)^{2}(3-\theta)^{2}}
\end{array}
$$

A crucial point to note is that both for $\pi_{1}>0$ and $\pi_{1}>0$ it is necessary that $\theta<1$. Without some privatization two banks cannot operate. Further, in the pure duopoly case, 
i.e. when $\theta=\rho=0$, each bank earns $\pi=\frac{R^{2}}{9 b}$.

The government and the private bank determine their respective choice variables, viz. $\theta$ and $\rho$, simultaneously. The private bank's owner chooses $\rho$ by maximizing (8) as follows

$$
\rho(\theta)=\frac{1+\theta}{5+\theta}
$$

This is the private bank's 'incentive reaction function', which is upward sloping in $\theta$ (see figure 2). Starting from a situation of complete nationalization, as the public bank increases divestment (i.e. reduces $\theta$ ), $D_{0}$ fall, $D_{1}$ rises (assuming $\rho<\frac{1}{2}$ ), the private bank then reduces its aggressiveness by cutting down on its sales incentives (or incentives to mobilize deposits). Alternatively stated, in a situation of pure duopoly, the private bank can enjoy its highest profit by setting $\rho=\frac{1}{5}$. Now if the government gets some stake in the rival bank, the private bank will experience a loss in profit. To make up for the lost profit, it will then raise its revenue incentive above $\frac{1}{5}$. Thus, greater the $\theta$, greater is $\rho$. Thus, managerial incentive is strategic complement to nationalization, or strategic substitute to privatization (which is measured by $(1-\theta)$ ).

To solve for the public bank's response, we maximize $V$ with respect to $\theta$. This yields

$$
\theta=\frac{2-\beta-\rho(1+\beta)}{\beta-\rho(3 \beta-1)}
$$

Notably, if $\beta=1$, optimal $\theta$ is 1 regardless of $\rho$. Several points are noteworthy. First, given $\rho<\frac{1}{2}$ and $\beta>1$, government's choice of privatization is partial. That is, $\theta \in(0,1)$. Second, when $\rho=0$, the resulting privatization is still partial, $0<\theta<1$. This is because the government is now concerned about profit, and driving depositor surplus to its maximum by setting $\theta=1$ involves inflicting loss on both banks. Given $\beta>1$ that cannot be optimal. Third, from the government's point of view nationalization (privatization) and managerial incentives are strategic substitutes (complements), as $\theta^{\prime}(\rho)<0$. This is exactly opposite of the perspective the private bank has. This is where mixed duopoly is crucially different from pure duopoly. As the government is not only concerned about 
private bank's profit, but also values the industry profit relatively more than depositor surplus, it internalizes some of the negative effects on profit that would follow from aggressive deposit mobilization by both banks. So when the private bank is expected to increase its deposit incentives (thus induce greater aggression by its manager in the second stage), the public bank divests its ownership to reduce the public bank's aggression, in order to contain the overall level of deposit mobilization. Thus, the government accommodates the private bank's aggression through privatization.

We derive the Nash equilibrium from the intersection of the two reaction functions, i.e. the nationalization reaction function of the public bank and the incentive reaction function of the private bank. Equilibrium $\theta$ and $\rho$ are given as follows

$$
\theta^{*}=\frac{3-2 \beta}{2 \beta-1}, \rho^{*}=\frac{1}{4 \beta-1}
$$

The solution is graphically shown in figure 2. In order to ensure an interior solution we need to assume that vertical intercept of the nationalization reaction function is greater than that of the incentive reaction function. This gives an upward limit on $\beta$, i.e. $\beta<\frac{3}{2}$. Beyond this level of $\beta$, the government becomes too profit oriented and hence would prefer to fully privatize the public bank. Therefore, for $\beta \in\left(1, \frac{3}{2}\right)$, (10) gives the equilibrium solution of $\theta$ and $\rho$.

\section{(Insert Figure 2 here)}

We can contrast this solution with two situations. First, if there were no private banks at all, what would be the optimal privatization? This can be determined by considering that if $D_{1}=0$ optimal $D_{0}$ would be $\frac{(1+\theta) R}{2 b}$ yielding $V^{M}=\frac{R^{2}}{8 b}(1+\theta)[(1+\theta+2 \beta(1-\theta)]$ and maximizing $v^{M}$ one obtains the optimal $\theta$ as $\frac{1}{2 \beta-1}$. This optimal privatization depends only on $\beta$. If however, $\beta=1, \theta^{*}=1$, i.e. divestment under monopoly is optimal only if there is profit concern. Second, if the government had no additional concern for profit (i.e. if $\beta=1$ ) its reaction curve would be vertical at $\theta=1$ and the only Nash equilibrium is then $\rho=\frac{1}{3}$ and $\theta=1$. This gives rise to a strange situation. Both banks make zero 
profit, and yet mobilize strictly positive deposits. At $\rho=\frac{1}{3}$ we can see from figure 1 both $D_{0}>0, D_{1}>0$, though the private bank remains aggressive in the deposit competition, its aggressiveness hardly pays off. But this is also not a situation where the private bank's best response is to exit. Thus, both banks will be stuck in a state of insolvency.

The mixed duopoly literature generally highlights the aggressiveness of public ownership and how it can force private firms to suffer loss and even exit; but what has not been considered at all is the potential response of the private firms. By using sales-oriented managerial incentives the private firms can prevent their exit from the industry, albeit earning only zero profit. So the managerial incentive can be seen as a survival strategy of private firms in the face of complete nationalization. In this environment, therefore, the government can make the mixed duopoly solvent by having some additional concern for profit. Of course, an immediate implication of the profit concern is that the government will be forced to internalize some of the strategic effects of managerial incentives, and therefore will divest more. We now summarize our main result.

Proposition 1 If the government is profit oriented, (i.e. $\beta>1$ ), the Nash equilibrium is characterized by the public bank being partially privatized and the private bank offering managerial incentives. Compared to the 'no managerial incentives' case, privatization will be greater. With an increase in $\beta$, equilibrium $\theta$ and $\rho$ fall.

While we have already discussed the equilibrium responses, here we consider the effect of an increase in $\beta$. A rise in the profit orientation of the government leads to greater privatization, and lower managerial incentives. Here the $\theta$ reaction curve shifts to the right, and the $\rho$ reaction curve remains unaffected. Hence equilibrium $\theta$ and $\rho$ decline. Thus, a higher profit orientation of the government induces both banks to move towards profit maximization behavior, and reduce their competitiveness.

Finally we check the social welfare implications of partial privatization and managerial incentives. Recall that $S W=\left(R-\frac{b D}{2}\right) D$, where $D$ is the total deposit. It can be easily seen that $S W$ is an increasing function of $D$ as long as $R>b D$ (which holds in equilibrium). Hence higher $D$ would mean higher social welfare. Therefore comparing social welfare in 
two situations boils down to comparing total deposits. From the second stage equilibrium deposits as given in (5) we derive the total deposit as

$$
D=\frac{R[2-\rho(1+\theta)]}{b(1-\rho)(3-\theta)}
$$

Next we substitute the equilibrium values of $\theta$ and $\rho$ from (9) in (10) and obtain the equilibrium value of $D$ which is

$$
D^{*}=\frac{R \beta}{b(2 \beta-1)}
$$

We would like to compare $D^{*}$ with the aggregate deposits of two cases: (i) pure duopoly without managerial incentives, and (ii) mixed duopoly without managerial incentives. In the first case, total deposit is $D=\frac{2 R}{3 b}$ which is obtained by substituting $\rho=\theta=0$ in (10). Since $\beta>1, D^{*}>\frac{2 R}{3 b}$. That is, social welfare is higher in the mixed duopoly as compared with the case of a private duopoly without managerial incentives. In the second case, we derive the aggregate deposit by substituting $\theta=\frac{2-\beta}{\beta}$ (which is the optimal value of $\theta$ when $\rho=0)$ in (10). This yields $D=\frac{R \beta}{b(2 \beta-1)}$ which is exactly same as $D^{*}$. Therefore, social welfare in the mixed duopoly with managerial incentives is same as that in a mixed duopoly without managerial incentives. Since $D$ is same in both situations, depositor surplus is also same and therefore the industry profit is also unchanged. But we know from (7) that the public bank's profit will fall with an increase in $\rho$. Then it must be the case that with managerial incentives the public bank's profit has fallen and the private bank's profit has risen, by exactly the same amount. Thus, the managerial incentive is playing a merely redistributive role with no effect on efficiency, which is entirely determined by the government's profit orientation.

We believe, this is a new insight into managerial incentives. In a pure duopoly managerial incentives (offered by two private banks) lead to mutual over-production, which generates higher social welfare, but lowers industry profit. In a mixed duopoly with endogenous privatization, the government internalizes the strategic effects on the private 
bank and thus softens the intensity of deposit competition by privatizing appropriately. The extent of privatization will however depend on the extent of profit orientation. If, for instance, the government is not at all profit oriented $(\beta=1)$, industry profit will be zero; but with managerial incentives the private bank will still be able to induce a redistribution of deposits with however no profit to redistribute. But if $\beta>1$, the government's concern for industry profit will be greater and its optimal privatization in the absence of managerial incentive will ensure an industry profit of $\pi=\frac{R^{2} \beta(\beta-1)}{b(2 \beta-1)}$. If now the private bank offers managerial incentives, the government will further divest, so that the industry profit and social welfare remain unchanged, but the private bank's profit rises at the expense of the public bank's and this redistribution of profit will take place via a redistribution of deposits. The following proposition summarizes our finding on social welfare.

Proposition 2 Social welfare in a mixed duopoly with equilibrium privatization and managerial incentives is higher than that in a private duopoly without managerial incentives; but it is same as that in a mixed duopoly without managerial incentives. Thus in a mixed duopoly, managerial incentives become merely redistributive having no efficiency effect.

\section{Interest rate competition}

Now we consider interest rate competition. Suppose deposits are differentiated as $D_{0}$ and $D_{1}$, which the public bank and the private bank collect in the market. These when invested fetches a common and constant rate of return $R$. The total cost to a representative depositor of supplying the two deposits is

$$
C\left(D_{0}, D_{1}\right)=b\left(\frac{D_{0}^{2}}{2}+\frac{D_{1}^{2}}{2}\right)+\delta D_{0} D_{1}
$$

where $\delta$ is the degree of substitutability between the two deposits; $0<\delta<b$. This is analogous to the total utility of a representative consumer in a model of differentiated goods in the price competition literature (see Singh and Vives, 1984). 
Considering the profit maximizing and price taking behavior of a representative depositor, who is trying to choose $D_{0}$ and $D_{1}$ so as to maximize $\pi=r_{0} D_{0}+r_{1} D_{1}-C\left(D_{0}, D_{1}\right)$, one obtains $r_{0}=\frac{\partial C}{\partial D_{0}}$ and $r_{1}=\frac{\partial C}{\partial D_{1}}$. From these we get the inverse supply curves for deposits as

$$
\begin{aligned}
& r_{0}=b D_{0}+\delta D_{1}, \\
& r_{1}=b D_{1}+\delta D_{0} .
\end{aligned}
$$

We may note that our earlier model can be retrieved from this model by setting $\delta=b$. From these inverse supply curves we derive the direct supply curves as

$$
\begin{aligned}
& D_{0}\left(r_{0}, r_{1}\right)=\frac{b}{b^{2}-\delta^{2}} r_{0}-\frac{\delta}{b^{2}-\delta^{2}} r_{1}, \\
& D_{1}\left(r_{0}, r_{1}\right)=\frac{b}{b^{2}-\delta^{2}} r_{1}-\frac{\delta}{b^{2}-\delta^{2}} r_{0} .
\end{aligned}
$$

Social welfare is defined as $W=R\left[D_{0}\left(r_{0}, r_{1}\right)+D_{1}\left(r_{0}, r_{1}\right)\right]-C\left(D_{0}\left(r_{0}, r_{1}\right), D_{1}\left(r_{0}, r_{1}\right)\right)$.

If the public bank were fully government owned, it would have maximized $W$ with respect to $r_{0}$ and set $\tilde{r}_{0}=\frac{(b-\delta)}{b} R+\frac{\delta}{b} r_{1}$. On the other hand, if the bank were fully privately owned, it would have maximized $\pi_{0}=\left[R-r_{0}\right] D_{0}\left(r_{0}, r_{1}\right)$ by setting $\hat{r}_{0}=\frac{R}{2}+\frac{\delta}{2 b} r_{1}$.

The interest rate reaction function of the partially nationalized bank is

$$
r_{0}=\theta \tilde{r}_{0}+(1-\theta) \hat{r}_{0}=\frac{[(1+\theta) b-2 \theta \delta]}{2 b} R+\frac{\delta(1+\theta)}{2 b} r_{1}
$$

Now consider the private bank. It hires a manager and offers her a managerial incentive scheme (as earlier explained), $M=(1-\rho) \pi_{1}+\rho R D_{1}\left(r_{0}, r_{1}\right)$, where $\pi_{1}=\left[R-r_{1}\right] D_{1}\left(r_{0}, r_{1}\right)$. As before, our interest is to see whether $\rho=0$ or otherwise. The interest rate reaction function of the private bank chosen by its manager is, therefore,

$$
r_{1}=\frac{R}{2(1-\rho)}+\frac{\delta}{2 b} r_{0}
$$


Solving (13) and (14) we obtain the equilibrium interest rates, conditional on $(\theta, \rho)$, as

$$
\begin{aligned}
& r_{0}=\frac{R b}{\left[4 b^{2}-\delta^{2}(1+\theta)\right]}\left[2\{b(1+\theta)-2 \delta \theta\}+\frac{\delta(1+\theta)}{1-\rho}\right], \\
& r_{1}=\frac{R}{\left[4 b^{2}-\delta^{2}(1+\theta)\right]}\left[\frac{2 b^{2}}{1-\rho}+\delta\{b(1+\theta)-2 \delta \theta\}\right] .
\end{aligned}
$$

It can be shown that while both $r_{0}$ and $r_{1}$ are increasing in $\rho$ as well as in $\theta, \theta$ has a stronger effect on $r_{0}$ than on $r_{1}$, and likewise $\rho$ has stronger effect on $r_{1}$ than on $r_{0}$ (see Appendix 1).

Now we consider the first stage problem of solving the simultaneous choice of $\theta$ and $\rho$. First consider the private bank's optimization. It will maximize $\pi_{1}=\left[R-r_{1}\right] D_{1}\left(r_{0}, r_{1}\right)$ where $r_{0}$ and $r_{1}$ are both functions of $\rho$ and $\theta$ as it would be given by (15) and (16). The first order condition for profit maximization can be derived as follows (see Appendix 2)

$$
\frac{\partial \pi_{1}}{\partial \rho}=\frac{\partial r_{0}}{\partial \rho}\left[-\left(R-r_{1}\right) \frac{\delta}{b^{2}-\delta^{2}}-\rho \frac{2 b}{\delta(1+\theta)}\left\{r_{1} \frac{b}{b^{2}-\delta^{2}}+D_{1}\right\}\right]
$$

Here $\frac{\partial r_{0}}{\partial \rho}>0$. So for the whole expression to be zero, the terms in square brackets must add up to zero. The first term is negative, and the second term will be positive if and only if $\rho<0$. That is, the private bank offers profit-linked incentives to its manager.

Finally, consider the government's optimization which determines optimal $\theta$. In this section we assume that government is purely social welfare maximizer, and therefore $\beta=1$. The fact that deposits are differentiated $(\delta<b)$ ensures that profit will be positive if the first bank is fully nationalized. By maximizing $W\left(r_{0}, r_{1}\right)$ with respect to $\theta$ we get

$$
\frac{\partial W}{\partial \theta}=\frac{\partial W}{\partial r_{0}} \frac{\partial r_{0}}{\partial \theta}+\frac{\partial W}{\partial r_{1}} \frac{\partial r_{1}}{\partial \theta}=\frac{\partial r_{0}}{\partial \theta}\left[\frac{\partial W}{\partial r_{0}}+\frac{\partial W}{\partial r_{1}} \frac{\delta}{2 b}\right]
$$

Since $\frac{\partial r_{0}}{\partial \theta}>0$, the sign of $\frac{\partial W}{\partial \theta}$ critically depends on both $\frac{\partial W}{\partial r_{0}}$ and $\frac{\partial W}{\partial r_{1}}$. Of these, first it can be shown that $\frac{\partial W}{\partial r_{1}}>0$ (see Appendix 3). Next the sign of $\frac{\partial W}{\partial r_{0}}$ needs to be determined. If this is non-negative, then complete nationalization is optimal. But if this is negative, 
then privatization (partial or complete) will be optimal. From the choice of the interest rate reaction function of the public bank we know that $\frac{\partial W}{\partial r_{0}}=0$ only when $\theta=1$. Under partial (or complete) privatization it is either positive or negative.

To ascertain this sign recall (13) and in particular $\tilde{r}_{0}$ and $\hat{r}_{0}$. Also recall that by definition at $\tilde{r}_{0}, \frac{\partial W}{\partial r_{0}}=0$. If $b \geq 2 \delta$, then $\tilde{r}_{0}>\hat{r}_{0}$ at all $r_{1}$. Therefore, the equilibrium $r_{0}$ cannot exceed $\tilde{r}_{0}$, which means $\frac{\partial W}{\partial r_{0}}$ must be non-negative. Hence, the first order condition in the government's optimization yields $\frac{\partial W}{\partial \theta}>0$, which implies that $\theta=1$ is optimal. In other words, 'no privatization' is optimal. This is shown in figure 3a in terms of interest reaction functions. The reaction function of a fully public bank $\tilde{r}_{0}\left(r_{1}\right)$ lies to the right of the reaction function of the fully private bank $\hat{r}_{0}\left(r_{1}\right)$. The resultant equilibrium in this case is given by point $E$ which corresponds to complete nationalization of the first bank and a profit-oriented incentive scheme in the second bank.

On the other hand, if $2 \delta>b$ then $\tilde{r}_{0}<(\geq) \hat{r}_{1}$ at all $r_{1}<(\geq) R \frac{(2 \delta-b)}{\delta}$. Then it is possible that in equilibrium we may have $\tilde{r}_{0}<r_{0}<\hat{r}_{0}$ (which is equivalent to saying that the equilibrium $\left.r_{1}<R \frac{(2 \delta-b)}{\delta}\right)$. In that case, we will have $\frac{\partial W}{\partial r_{0}}<0$ which gives rise to the possibility that $\frac{\partial W}{\partial \theta}=0$ implying partial privatization. Figure $3 \mathrm{~b}$ shows that the reaction function of a fully nationalized bank will lie to the left of the fully private bank's reaction function. Here, the first bank is partially privatized leading to a reaction function which is a weighted average of $\tilde{r}_{0}\left(r_{1}\right)$ and $\hat{r}_{0}\left(r_{1}\right)$. The resultant equilibrium is $E^{\prime}$.

Proposition 3 Under interest rate competition, the private bank will offer a profit-oriented (or deposit-penalizing) incentive scheme to its manager by choosing $\rho<0$, while the public bank may or may not be privatized. When $b \geq 2 \delta$, the public bank is not privatized at all. When $b<2 \delta$, partial privatization may occur.

As was the case with deposit competition, managerial incentives are found to be an effective means of protecting (and even enhancing) profit, which would otherwise be eaten away by the rival bank's nationalization. However, the total industry profit will not remain unchanged in this case, because of the product differentiation. Since $r_{1}<R$ and $r_{0}<R$, profit is always positive. 
Notably, now the incentive is in the direction of profit. The manager will be induced to lower the interest rate by making him more cost-sensitive. The public bank also reciprocates by reducing its interest rate due to strategic complementarity of the two interest rates (see Fershtman and Judd, 1987). As for privatization, the government faces two opposite concerns: induce an increase in the interest rate in the first market so that the depositor surplus would rise, but also pay attention to the adverse effect that the second market would suffer in the process.

The intensity of the tension between these two concerns depends on the magnitude of $\delta$ relative to $b$. When $\delta$ is fairly small (i.e. when the two markets are fairly apart), the effect of an increase in $r_{0}$ will have a muted effect on the second market. The government, therefore, would like to raise $r_{0}$ toward $R$ by going for complete nationalization; the private bank does its best by offering profit-oriented incentives (see figure 3a). On the other hand, when $\delta$ is sufficiently large (in the sense that $2 \delta>b$ ) two markets are very close, and the concern for the effect on the second market overrides the desire to raise $r_{0}$. In this case, the government is accommodative (see figure $3 \mathrm{~b}$ ). In fact, it is so accommodative that often it would set an interest rate $\left(r_{0}\right)$ well below the optimal level of a fully private bank. Here privatization helps to increase the interest rate a bit and in turn the depositor surplus increases as well.

(Insert Figure 3 here)

\section{Conclusion}

This paper explores optimal partial privatization and managerial incentives in the framework of a 'mixed oligopoly' involving a partly divested public bank. We show that if the government is profit oriented, then the public bank has to be partially privatized, and in response the private bank will offer revenue-linked incentives to its manager. But privatization will be greater than in the case where the private bank does not offer managerial 
incentives. Thus, managerial incentives and partial privatization appear to be integral features of mixed duopoly. Moreover, profit orientation and managerial incentives appear to be playing two distinct roles. Profit orientation determines the industry profit and managerial incentives determine its distribution between the two banks. This merely redistributive role of managerial incentive seems to be possible only in a mixed duopoly.

A policy implication of this result is that a profit oriented government should be prepared to privatize the state owned bank when faced with aggressive strategies by the private bank e.g. managerial incentives. Although accommodating the private bank's aggression hurts the public bank's profit but it prevents an erosion of industry profit which is important for financial stability. We also consider the case of interest rate competition where we show that while the private bank's strategy is to offer profit-linked incentives, even a purely welfare maximizing government chooses partial privatization when the two deposits are close substitutes. However the government opts for full nationalization when the two deposits are sufficiently differentiated. This result implies that the government will face pressure to privatize the state owned bank if it competes with the private bank in a related market but can choose to fully nationalize if the two markets are sufficiently segmented.

Our analysis sheds some light on the recent global financial crisis, which started in 2007. Many banks and financial institutions have been nationalized or received government bailouts to protect depositors' interests. Though we have not modeled bank competition in the loan market, it is foreseeable that our model can be extended in this direction and the consequences of aggressive (and irresponsible) lending (effected by managerial incentives), which is believed to be a cause of the crisis, can be suitably studied. On the deposit side, we can say that nationalization helps to protect the depositors' interest in times of crisis. Our analysis shows that when the government nationalizes one bank other private banks may offer more aggressive incentives to their managers to mobilize deposits; but such interactions between public and private banks may be good for the economy provided the competition in the loan market does not encourage excessive risk taking. 


\section{REFERENCES}

1. Aghion, P., Bolton, P. and Fries, S. (1999): "Optimal Design of Bank Bailouts: The Case of Transition Economies." Journal of Institutional and Theoretical Economics $155(1): 51-70$.

2. Allen, F. and Gale, D. (2004): "Competition and Financial Stability." Journal of Money, Credit and Banking 36(3): 453-80.

3. Barth, J.R., Caprio, G. and Levine, R. (2001): "Banking Systems Around the Globe: Do Regulation and Ownership Affect Performance and Stability?" In Financial Supervision and Regulation: What Works and What Doesn't? edited by F. Mishkin, National Bureau of Economic Research.

4. Eriksson,T. (2005): "Managerial pay and executive turnover in the Czech and Slovak Republics," Economics of Transition 13(4): 659-677.

5. Fershtman, C. (1990): "The Interdependence between Ownership Status and Market Structure: The Case of Privatization." Economica 57: 319-328.

6. Fershtman, C. and Judd, K. L. (1987): "Equilibrium Incentives in Oligopoly." American Economic Review 77: 927-940.

7. Hubbard, R.G. and Palia, D. (1995): "Executive pay and performance Evidence from the U.S. banking industry." Journal of Financial Economics 39(1): 105-130.

8. Jensen, M.C., Murphy, K.J. and Wruck, E.G. (2004): Remuneration: Where Weve Been, How We Got to Here, What Are the Problems, and How to Fix Them." Finance Working Paper 44/2004, European Corporate Governance Institute.

9. Kato, T. and Long, C. (2006): "Executive Compensation, Firm Performance, and Corporate Governance in China: Evidence from Firms Listed in the Shanghai and Shenzhen Stock Exchanges." Economic Development and Cultural Change 54(3): 945-983. 
10. Kumar, A. and Saha, B. (2008): "Spatial competition in a mixed duopoly with one partially privatized firm." Journal of Comparative Economics, 36: 326-341.

11. Matsumura, T. (1998): "Partial Privatization in Mixed Duopoly." Journal of Public Economics 70: 473-483.

12. Purroy, P. and Salas, V. (2000): "Strategic Competition in Retail Banking under Expense Preference Behavior." Journal of Banking and Finance 24: 809-824.

13. Saha, B. and Sensarma, R. (2004): "Divestment and bank competition." Journal of Economics 81(3): 223-247.

14. Singh, N. and Vives, X. (1984): "Price and Quantity Competition in a Differentiated Duopoly." RAND Journal of Economics 15(4): 546-554.

15. Sherif, K., Borish, M. and Gross, A. (2003): "State-Owned Banks in the Transition: Origins, Evolution, and Policy Responses." Washington, DC : World Bank.

16. Shirai, Sayuri (2002): "Banking Sector Reforms in India and China-Does India's Experience Offer Lessons for China's Future Reform Agenda," Asia-Pacific Development Journal 9(2): 51-82.

17. Sklivas S. (1987): "The Strategic Choice of Managerial Incentives", RAND Journal of Economics 18: 452-458.

18. Vickers J. (1985): "Delegation and the Theory of the Firm", Economic Journal 95: $138-147$. 


\section{APPENDIX 1: EFFECTS OF $\rho$ AND $\theta$ ON $r_{0}$ AND $r_{1}$}

From (15) and (16) we derive the following

$$
\begin{aligned}
\frac{\partial r_{0}}{\partial \rho} & =\frac{R b \delta(1+\theta)}{\left[4 b^{2}-\delta^{2}(1+\theta)\right](1-\rho)^{2}}>0 \\
\frac{\partial r_{1}}{\partial \rho} & =\frac{\partial r_{0}}{\partial \rho} \frac{2 b}{\delta(1+\theta)}>0 \\
\frac{\partial r_{0}}{\partial \theta} & =\frac{4 R b}{\left[4 b^{2}-\delta^{2}(1+\theta)\right]^{2}(1-\rho)}\left[2 b^{2}(b-2 \delta)(1-\rho)+\delta^{3}(1-\rho)+b^{2} \delta\right]>0 \\
\frac{\partial r_{1}}{\partial \theta} & =\frac{\partial r_{0}}{\partial \theta} \frac{\delta}{2 b}>0 .
\end{aligned}
$$

Since $2 b>\delta(1+\theta)$, we have $\frac{\partial r_{1}}{\partial \rho}>\frac{\partial r_{0}}{\partial \rho}$ and $\frac{\partial r_{1}}{\partial \theta}<\frac{\partial r_{0}}{\partial \theta}$.

\section{APPENDIX 2: DERIVATION OF EQUATION (17)}

Consider the private bank owner's maximization problem

$$
\frac{\partial \pi_{1}}{\partial \rho}=\left(R-r_{1}\right) \frac{\partial D_{1}}{\partial r_{0}} \frac{\partial r_{0}}{\partial \rho}+\left[\left(R-r_{1}\right) \frac{\partial D_{1}}{\partial r_{1}}-D_{1}\right] \frac{\partial r_{1}}{\partial \rho}
$$

Substituting the first order condition of the manager's optimization problem (regarding the choice of $\left.r_{1}\right)$ we replace $\left[\left(R-r_{1}\right) \frac{\partial D_{1}}{\partial r_{1}}-D_{1}\right]$ by $\left[-\rho\left\{r_{1} \frac{\partial D_{1}}{\partial r_{1}}+D_{1}\right\}\right]$, and rewrite the owner's first order condition as

$$
\frac{\partial \pi_{1}}{\partial \rho}=\left(R-r_{1}\right) \frac{\partial D_{1}}{\partial r_{0}} \frac{\partial r_{0}}{\partial \rho}+\left[-\rho\left\{r_{1} \frac{\partial D_{1}}{\partial r_{1}}+D_{1}\right\}\right] \frac{\partial r_{1}}{\partial \rho}
$$

Further substitute $\frac{\partial D_{1}}{\partial r_{0}}=-\frac{\delta}{b^{2}-\delta^{2}}, \frac{\partial D_{1}}{\partial r_{1}}=\frac{b}{b^{2}-\delta^{2}}$ and $\frac{\partial r_{1}}{\partial \rho}=\frac{\partial r_{0}}{\partial \rho} \frac{2 b}{\delta(1+\theta)}$ and obtain (17). 


\section{APPENDIX 3: PROOF OF $\frac{\partial W}{\partial r_{1}}>0$}

From the expression of $W$ we derive the following

$$
\begin{aligned}
\frac{\partial W}{\partial r_{1}} & =R\left(\frac{\partial D_{0}}{\partial r_{1}}+\frac{\partial D_{1}}{\partial r_{1}}\right)-\frac{\partial C}{\partial D_{0}} \frac{\partial D_{0}}{\partial r_{1}}-\frac{\partial C}{\partial D_{1}} \frac{\partial D_{1}}{\partial r_{1}} \\
& =R\left(-\frac{\delta}{b^{2}-\delta^{2}}+\frac{b}{b^{2}-\delta^{2}}\right)+r_{0} \frac{\delta}{b^{2}-\delta^{2}}-r_{1} \frac{b}{b^{2}-\delta^{2}} \\
& =\left(R-r_{1}\right) \frac{b}{b^{2}-\delta^{2}}-\left(R-r_{0}\right) \frac{\delta}{b^{2}-\delta^{2}}
\end{aligned}
$$

To ascertain the sign of $\frac{\partial W}{\partial r_{1}}$ we need to compare $r_{1}$ and $r_{0}$. We first show that if $\rho \leq 0$ and $\theta \leq 1$, then $r_{1}(\rho, \theta) \leq r_{0}(\rho, \delta)$. From (15) and (16) note that $r_{1}(.) \leq r_{0}($.$) implies$

$$
b \delta \theta+(2 b-\delta)[(1-\rho)\{b(1+\theta)-2 \delta \theta\}-b] \geq 0 .
$$

The first term is clearly non-negative. For the second term to be non-negative, we must have $(1-\rho)\{b(1+\theta)-2 \delta \theta\} \geq b$. Examine this inequality by setting the lowest value of the left hand side expression. Since $b(1+\theta)-2 \delta \theta$ is increasing (non-increasing) if $b>(\leq) 2 \delta$, the lowest value of the left hand side expression occurs at $\theta=0$ (when $b>2 \delta$ ), in which case the inequality reduces to $(1-\rho) b \geq b$, which clearly holds due to the fact that $\rho \leq 0$. Similarly, if $b \leq 2 \delta$, evaluate the inequality at $\theta=1$, which gives $(1-\rho) 2(b-\theta) \geq b$. This also clearly holds. Hence, at all $\rho \leq 0, \theta \in[0,1]$ we have $(1-\rho)\{b(1+\theta)-2 \delta \theta\} \geq b$ which implies $r_{1}<r_{0}$. Consequently $\left(R-r_{1}\right)>\left(R-r_{0}\right)$ and given $b>\delta$ we can conclude that $\frac{\partial W}{\partial r_{1}}>0$. 


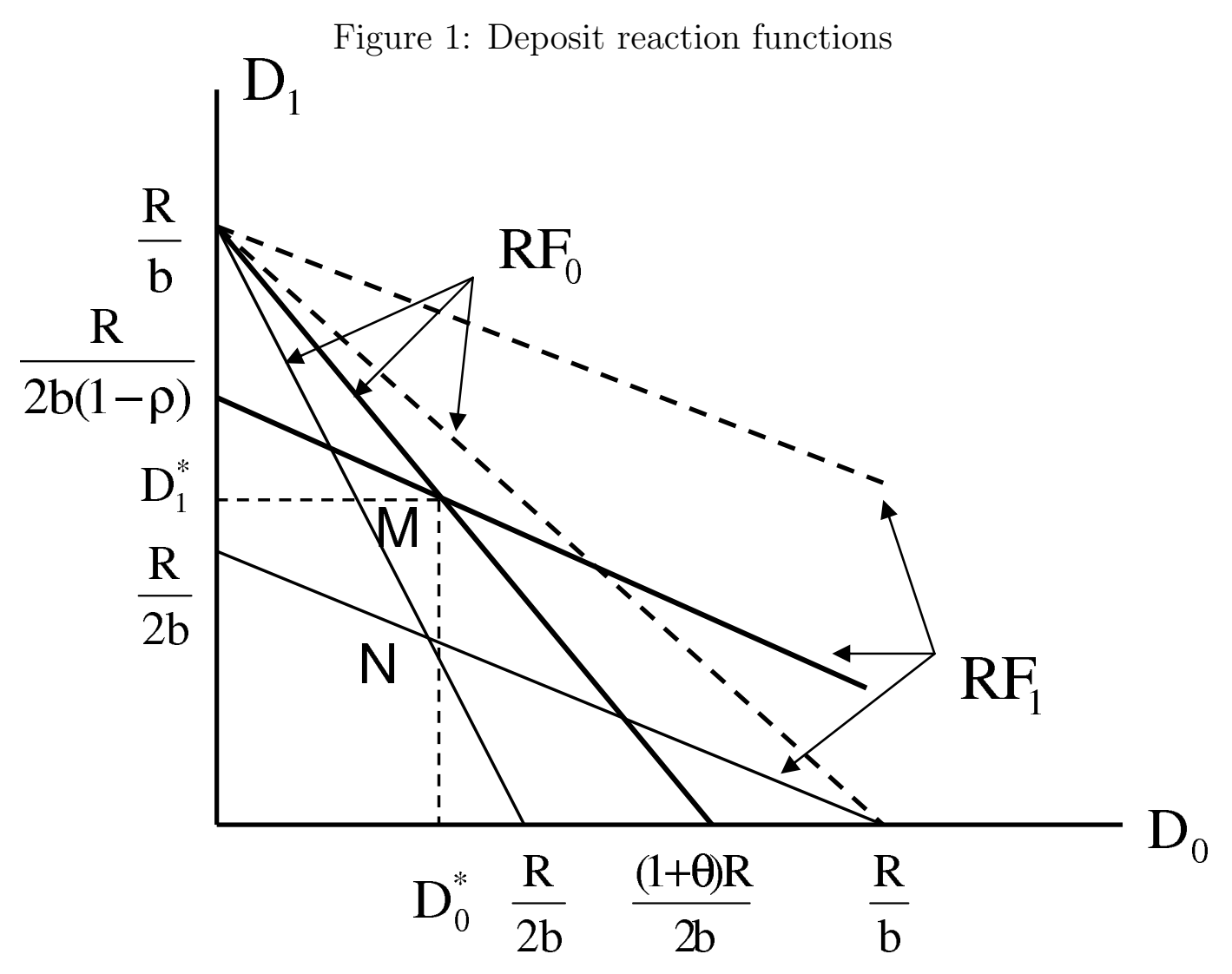


Figure 2: Equilibrium privatization and managerial incentives $\rho$

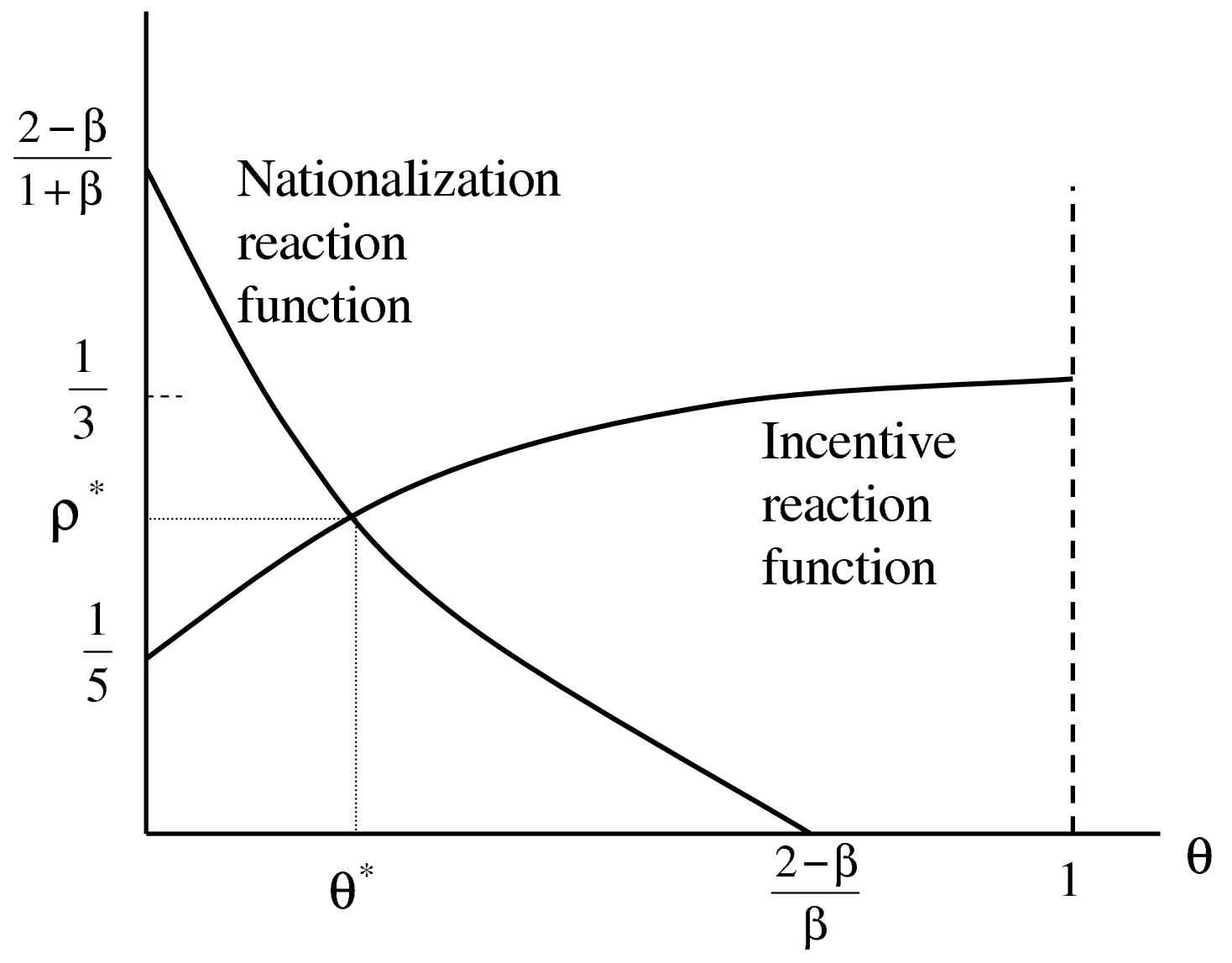


Figure 3: Interest rate reaction functions

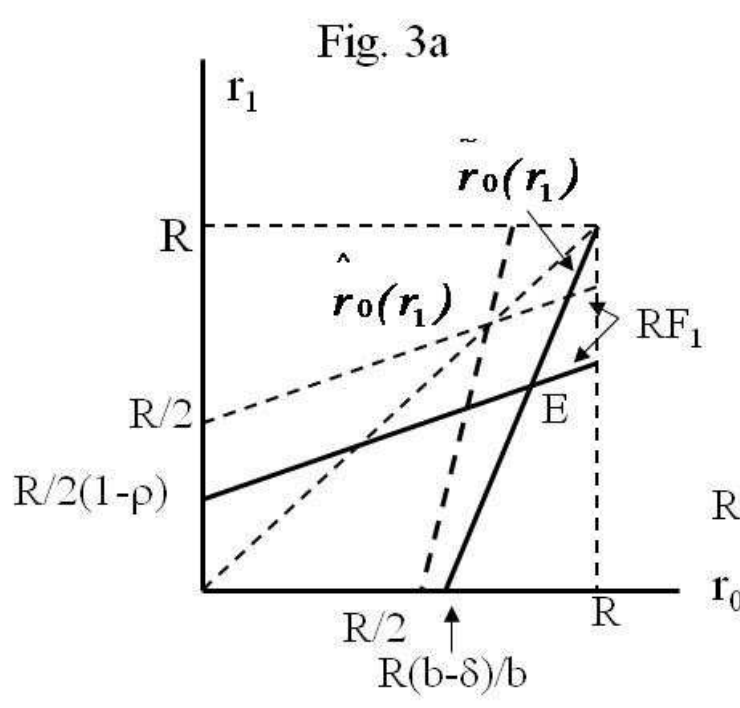

Fig. $3 b$

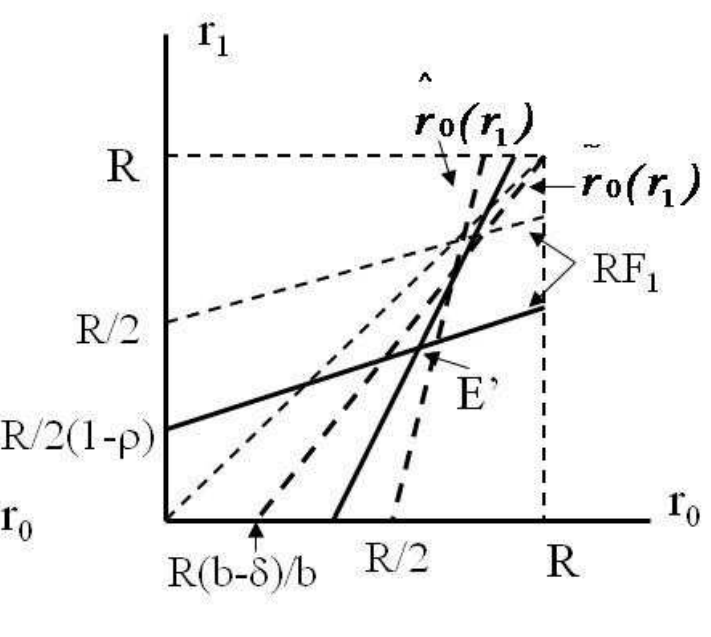

